Article

\title{
Identification of Enzymes Oxidizing the Tyrosine Kinase Inhibitor Cabozantinib: Cabozantinib Is Predominantly Oxidized by CYP3A4 and Its Oxidation Is Stimulated by cyt $b_{5}$ Activity
}

\author{
Radek Indra $^{1, *}$, Katarína Vavrová ${ }^{1}\left(\mathbb{D}\right.$, Petr Pompach ${ }^{1}$, Zbyněk Heger ${ }^{2,3}$ and Petr Hodek ${ }^{1}$ \\ 1 Department of Biochemistry, Faculty of Science, Charles University, Albertov 6, 12800 Prague 2, \\ Czech Republic; katarina.vavrova@natur.cuni.cz (K.V.); petrpompach@gmail.com (P.P.); \\ petr.hodek@natur.cuni.cz (P.H.) \\ 2 Department of Chemistry and Biochemistry, Mendel University in Brno, Zemedelska 1, 61300 Brno, \\ Czech Republic; zbynek.heger@mendelu.cz \\ 3 Central European Institute of Technology, Brno University of Technology, Purkynova 656/123, 61200 Brno, \\ Czech Republic \\ * Correspondence: radek.indra@natur.cuni.cz; Tel.: +420-221-951-285
}

Received: 20 October 2020; Accepted: 26 November 2020; Published: 28 November 2020

check for updates

\begin{abstract}
Herein, the in vitro metabolism of tyrosine kinase inhibitor cabozantinib, the drug used for the treatment of metastatic medullary thyroid cancer and advanced renal cell carcinoma, was studied using hepatic microsomal samples of different human donors, human recombinant cytochromes P450 (CYPs), flavin-containing mono-oxygenases (FMOs) and aldehyde oxidase. After incubation with human microsomes, three metabolites, namely cabozantinib $N$-oxide, desmethyl cabozantinib and monohydroxy cabozantinib, were detected. Significant correlations were found between CYP3A4 activity and generation of all metabolites. The privileged role of CYP3A4 was further confirmed by examining the effect of CYP inhibitors and by human recombinant enzymes. Only four of all tested human recombinant cytochrome P450 were able to oxidize cabozantinib, and CYP3A4 exhibited the most efficient activity. Importantly, cytochrome $b_{5}\left(c y t b_{5}\right)$ stimulates the CYP3A4-catalyzed formation of cabozantinib metabolites. In addition, cyt $b_{5}$ also stimulates the activity of CYP3A5, whereas two other enzymes, CYP1A1 and 1B1, were not affected by cyt $b_{5}$. Since CYP3A4 exhibits high expression in the human liver and was found to be the most efficient enzyme in cabozantinib oxidation, we examined the kinetics of this oxidation. The present study provides substantial insights into the metabolism of cabozantinib and brings novel findings related to cabozantinib pharmacokinetics towards possible utilization in personalized medicine.
\end{abstract}

Keywords: cabozantinib; cytochrome P450; tyrosine kinase inhibitor; cytochrome $b_{5}$

\section{Introduction}

In general, differences in drug absorption, distribution, metabolism and excretion result in interindividual variations in the pharmacokinetics of a drug, if patients are administered a uniform dose of the drug [1]. Among patients with benign diseases treated with common drugs, relatively small differences in drug pharmacokinetics including metabolism are observed because of the wide therapeutic windows. However, in cancer chemotherapy, serious clinical consequences may occur from small alterations in drug metabolism affecting the drug pharmacokinetics [2].

Cabozantinib (N'1-\{4-[(6,7-dimethoxyquinolin-4-yl)oxy]phenyl\}-N1-(4-fluorophenyl)cyclopropane -1,1-dicarboxamide) exhibits substantial antitumor activities in patients with multiple cancer types: 
medullary thyroid cancer [3], breast cancer [4,5], hepatocellular carcinoma [6,7], non-small cell lung cancer [8,9], prostate cancer [10,11], renal-cell carcinoma [12,13] and pancreatic cancer [14]. Pursuant to these studies, cabozantinib was approved as COMETRIQ ${ }^{\circledR}$ for treatment of metastatic medullary thyroid cancer in 2012 and as CABOMETYX ${ }^{\mathrm{TM}}$ for patients with advanced renal cell carcinoma in 2016. Moreover, cabozantinib as CABOMETYX ${ }^{\mathrm{TM}}$ was approved in 2019 for hepatocellular carcinoma patients who have been previously treated with sorafenib. It acts as a tyrosine kinase inhibitor (TKI), affecting vascular endothelial growth factor receptor 2 (VEGFR-2) and hepatocyte growth factor receptor MET [15-18]. It also inhibits several other kinases, including KIT, RET and AXL [15]. Therefore, cabozantinib is considered a multiple TKI, affecting tumor angiogenesis, invasion and metastasis. Although cabozantinib is well tolerated, its administration is associated with frequent treatment-limiting adverse effects, and dose reductions are commonplace. The most frequently reported adverse effects in patients with renal-cell carcinoma are diarrhea, palmar-plantar erythrodysesthesia syndrome, fatigue and hypertension $[4,7,19]$.

Cabozantinib is efficiently bound by proteins in human plasma ( $\geq 99.7 \%)$ [20]. Recent work with healthy volunteers revealed that cabozantinib was eliminated primarily in feces and extensively metabolized up to 17 metabolites identified by liquid chromatography-tandem mass spectrometry [18]. These metabolites were represented by hydroxy-derivates, amide cleavage products, glucuronide conjugates and sulfates. Thus, enzymes of phase I and also phase II participate in cabozantinib metabolism in the human body. Because of limited information, which indicates lower efficiency of individual cabozantinib metabolites [18], knowledge of the cabozantinib metabolic pathway is crucial for the improvement of treatment protocols and prognostic accuracy.

In the present study, we investigated the in vitro metabolism of cabozantinib in cell-free systems. We used human hepatic subcellular systems (microsomes) containing enzymes that are responsible for the first-pass metabolism of drugs. In addition, individual recombinant human cytochromes P450 (CYPs), flavin-containing mono-oxygenases (FMOs) and aldehyde oxidase (AO) were employed to identify enzymes capable of metabolizing cabozantinib. Since CYP3A4 was identified as the major enzyme metabolizing cabozantinib in human liver, the mechanism of CYP3A4-catalyzed oxidation was characterized in detail.

\section{Materials and Methods}

\subsection{Chemicals and Materials}

Cabozantinib was from MedChemExpress (Monmouth Junction, NJ, USA). Standard of cabozantinib $\mathrm{N}$-oxide was purchased from Toronto Research Chemicals (Toronto, Canada). Ketoconazole, NADPH and other chemicals were all purchased from Merck (Darnstadt, Germany). The purity of all chemicals met the standards of American Chemical Society, unless otherwise noted. Male human hepatic microsomes (pooled sample) (sample LOT: 3043885) were from Gentest Corp. (Woburn, MA, USA). Microsomes from livers of twelve human donors were obtained from Gentest Corp. (Woburn, MA, USA) (Lot. no. HG43-1, HG103, HG74, HG93, HG24, HG27, HG23, HG32, HK31, HK34, HG03 and HG42). Each human microsomal sample was characterized for CYP, FMO, total protein contents and specific CYP activities by Gentest Corp. and reanalyzed by us by assays described in the protocols of Gentest Corp. Our data were similar to those reported by Gentest Corp. (Table 1). Human recombinant enzymes were used in the forms of Supersomes ${ }^{\mathrm{TM}}$ and obtained from Corning (Corning, NY, USA). In Supersomes ${ }^{\mathrm{TM}}$, microsomal fractions were isolated from insect cells that were transfected with baculovirus constructs containing cDNA of human CYP enzymes (CYP1A1/2, 1B1, 2A6, 2B6, 2C8/9/18/19/, 2D6, 2E1, 3A4). The Supersomes ${ }^{\mathrm{TM}}$ also express NADPH:CYP oxidoreductase (POR). However, because they are microsomes (particles of broken endoplasmic reticulum), other enzymes (proteins) of the endoplasmic reticulum membrane (like NADH:cytochrome $b_{5}$ reductase and cytochrome $b_{5}$ ) are also expressed at basal levels in these Supersomes ${ }^{\mathrm{TM}}$. We also utilized Supersomes ${ }^{\mathrm{TM}}$, which overexpressed cytochrome $b_{5}$, in a molar ratio of CYP to cytochrome $b_{5}$ of 1 to 5 . In Supersomes ${ }^{\mathrm{TM}}$, where cytochrome $b_{5}$ was not 
overexpressed (see above), pure cytochrome $b_{5}$ was added to reach a molar ratio of CYP to cytochrome $b_{5}$ of 1 to 5 . Reconstitution of Supersomes ${ }^{\mathrm{TM}}$ with purified cytochrome $b_{5}$ was performed as described previously [21-23]. Human recombinant FMOs and AO were also used in the forms of Supersomes ${ }^{\mathrm{TM}}$ (Gentest Corp., Woburn, MA, USA). These microsomal fractions were isolated from insect cells that are transfected with baculovirus constructs containing cDNA of human FMO1, FMO3, FMO5 or AO enzymes.

\subsection{Oxidation of Cabozantinib by Hepatic microsomes and Human Recombinant Enzymes}

Unless stated otherwise, incubation mixtures used to study cabozantinib metabolism contained the following in a final volume of $500 \mu \mathrm{L}$ for incubations containing hepatic microsomes and 250 $\mu \mathrm{L}$ for incubations with recombinant enzymes (Supersomes ${ }^{\mathrm{TM}}$ ): $100 \mathrm{mM}$ potassium phosphate buffer (pH 7.4); $1 \mathrm{mM}$ NADPH; human hepatic microsomes (0.25 mg protein) or human recombinant CYPs, FMOs or AO in Supersomes ${ }^{\mathrm{TM}}(25 \mathrm{pmol})$; and $50 \mu \mathrm{M}$ cabozantinib dissolved in 5 (respectively 2.5) $\mu \mathrm{L}$ dimethyl sulfoxide. The reaction was initiated by adding NADPH. In control incubations, either microsomes or CYP (FMO, AO) or NADPH were omitted. Incubations were performed at $37^{\circ} \mathrm{C}$ for $20 \mathrm{~min}$ in open plastic Eppendorf tubes; cabozantinib oxidation was linear up to 30 min of incubation. The reaction was stopped by extraction with ethyl acetate $(2 \times 1 \mathrm{~mL})$. Extracts were evaporated and dissolved in $50 \mu \mathrm{L}$ methanol, and high-performance liquid chromatography (HPLC) analysis was used to separate cabozantinib and its metabolites. HPLC conditions were as follows: Nucleosil ${ }^{\circledR}$ EC 100-5 C18 reverse-phase column $(150 \times 4.6 \mathrm{~mm}$, Macherey Nagel, Duren, Germany); the eluent was $5 \mathrm{mM}$ ammonium acetate in water ( $\mathrm{pH}$ ) containing $60 \%$ acetonitrile with a flow rate of $1 \mathrm{~mL} / \mathrm{min}$; injection was $10 \mu \mathrm{L}$; and detection was at $254 \mathrm{~nm}$. Cabozantinib metabolites separated by HPLC were characterized by mass spectroscopy (see further details below). The recoveries of cabozantinib metabolites were approximately $95 \%$.

\subsection{Identification of Cabozantinib Metabolites by Mass Spectrometry}

Cabozantinib metabolites were identified by liquid chromatography coupled with Q-ToF mass spectrometer. Samples were re-suspended in $50 \mu \mathrm{L}$ of methanol. Ten microliters was injected via autosampler (Ultimate 3000 UHPLC system, Thermo Fisher Scientific, Waltham, MA, USA) on reverse-phase $\mathrm{C} 18$ column $\left(150 \times 4.6 \mathrm{~mm}\right.$, Macherey Nagel) heated at $37^{\circ} \mathrm{C}$. Cabozantinib metabolites were eluted isocratically by $5 \mathrm{mM}$ ammonium acetate in water $(\mathrm{pH}$ ) containing $60 \%$ acetonitrile solvent at a flow rate of $0.6 \mathrm{~mL} / \mathrm{min}$ and measured by Q-ToF mass spectrometer (maXis Plus, Bruker Daltonics, Bremen, Germany) operating in positive data-dependent mode. Mass range was 50-700 m/ , number of precursors was 3 and a spectral rate was set at $5.00 \mathrm{~Hz}$. Mass spectrometer was externally calibrated using NaTFA. Data were processed by DataAnalysis 4.3 software (Bruker Daltonics).

\subsection{Inhibition Study}

Inhibition studies in pooled human liver microsomes were conducted with six inhibitors. The inhibitors employed were as follows: $\alpha$-Naphthoflavone $(\alpha-\mathrm{NF})$, which inhibits CYP1A1 and 1A2; sulfaphenazole, which inhibits CYP2C; quinidine, which inhibits CYP2D; diethyldithiocarbamate (DDTC), which inhibits CYP2E1 and CYP2A; ketoconazole, which inhibits CYP3A; and CYP3cide, which inhibits CYP3A4. The $\mathrm{IC}_{50}$ values for employed inhibitors were determined by the procedure described previously [24]. For experiments, inhibitors were dissolved in $5 \mu \mathrm{L}$ methanol and incubated at $37^{\circ} \mathrm{C}$ for $10 \mathrm{~min}$ with $50 \mu \mathrm{M}$ cabozantinib followed by the addition of NADPH. Then, mixtures were incubated for a further $20 \mathrm{~min}$ at $37^{\circ} \mathrm{C}$. Formation of cabozantinib metabolites was analyzed by HPLC as described above.

\subsection{Contributions of CYP Enzymes to Formation of Cabozantinib Metabolites in Human Livers}

In order to calculate the contributions of individual CYPs to the formation of individual cabozantinib metabolites in human liver, we measured the velocities of their formation by the Supersomal CYP enzyme 
systems containing $c y t b_{5}$ and combined these velocities with data on the average expression levels of individual CYPs in human liver derived from [25-27]. Specifically, the contributions of each CYP to cabozantinib metabolite formation in liver were calculated by dividing the relative metabolite-forming activity of each CYP (rate of formation multiplied by amounts of this CYP in human liver) by the total relative activities of all metabolite-forming CYPs.

\subsection{Statistical Analysis}

Data are expressed as mean \pm SD. Data were analyzed using GraphPad Prism 7 (San Diego, CA, USA) using ANOVA with post-hoc Tukey HSD Test. All $p$-values are two-tailed and considered significant at the 0.05 level. Statistical associations between CYP- and FMO-linked catalytic activities in human hepatic microsomal samples and amounts of cabozantinib metabolites were determined by linear regression using Statistical Analysis System software version 6.12. Correlation coefficients (r) were based on a sample size of twelve for human microsomes. All $p$-values are two-tailed and considered significant at the 0.05 level.

\section{Results}

\subsection{Oxidation of Cabozantinib by Human Hepatic Microsomes and Correlation of CYPs Activities with Cabozantinib Oxidation}

First, we investigated the function of the human hepatic microsomal system, which contains biotransformation enzymes, from individual donors to catalyze the oxidation of cabozantinib. All hepatic microsomes oxidized cabozantinib to three metabolites that were separated by HPLC and identified by mass spectroscopy. In the case of cabozantinib $N$-oxide, the structure was confirmed by analyzing the standard of this metabolite. The formation of cabozantinib metabolites was dependent on NADPH, and without it, no oxidation of cabozantinib was detected (Figure 1). The predominant metabolite was identified as cabozantinib $N$-oxide $\left(\mathrm{M}_{3}\right)$. Two other metabolites were identified as monohydroxy cabozantinib $\left(\mathrm{M}_{1}\right)$ and desmethyl cabozantinib $\left(\mathrm{M}_{2}\right)$.

The correlation analysis between enzyme activities of different CYPs in single-donor microsomes and the amounts of individual cabozantinib metabolites formed in each microsomal sample (Table 1) were used to examine the role of specific human CYPs in their generation. The highest correlation for all three metabolites was found with testosterone-6 $\beta$-hydroxylation (a marker for CYP3A4): cabozantinib $N$-oxide $(\mathrm{r}=0.947 ; p<0.001)$, monohydroxy cabozantinib $(\mathrm{r}=0.918 ; p<0.001)$ and desmethyl cabozantinib ( $\mathrm{r}=0.935 ; p<0.001)$. Significant correlations were also found between individual metabolites and activities of three other cytochromes P450 (CYP2A6, 2B6 and 2C8; Table 2). These results indicate that these four enzymes might be responsible for the formation of cabozantinib metabolites in human liver. However, there are high cross-correlations between testosterone-6 $\beta$-hydroxylation and coumarine-7-hydroxylase (marker of CYP2A6; $\mathrm{r}=0.786 ; p<0.01$ ), testosterone-6 $\beta$-hydroxylation and (S)-mephenytoin- $N$-demethylase (marker of CYP2B6; $\mathrm{r}=0.823$; $p<0.01$ ), testosterone-6 $\beta$-hydroxylation and paclitaxel- $6 \alpha$-hydroxylase (marker of CYP2C $8 ; \mathrm{r}=0.751$; $p<0.01)$ and $(S)$-mephenytoin- $N$-demethylase and paclitaxel- $6 \alpha$-hydroxylase $(\mathrm{r}=0.930 ; p<0.001)$ within these liver microsomes samples. To clarify these correlations, multivariate analysis was used to investigate the dependence of metabolite formation on these CYP activities. Activities of CYP2A6, -2B6 and -2C8 in each microsomal sample were combined in pairs with the activities of CYP3A4 to see if any combination of the activities led to an improvement in the correlation with CYP3A4. We can conclude that CYP3A4 is in fact the enzyme responsible for cabozantinib oxidation. 
A

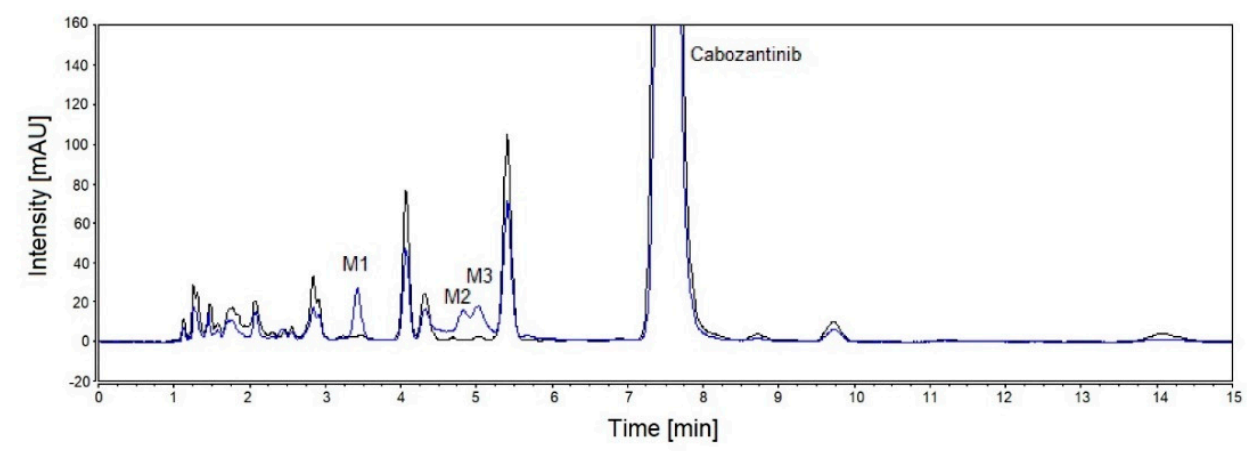

B

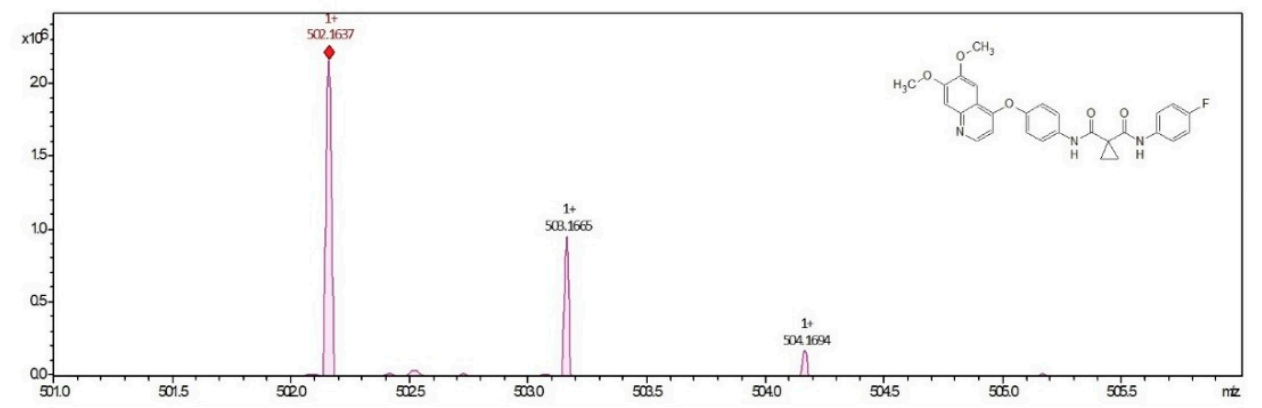

C

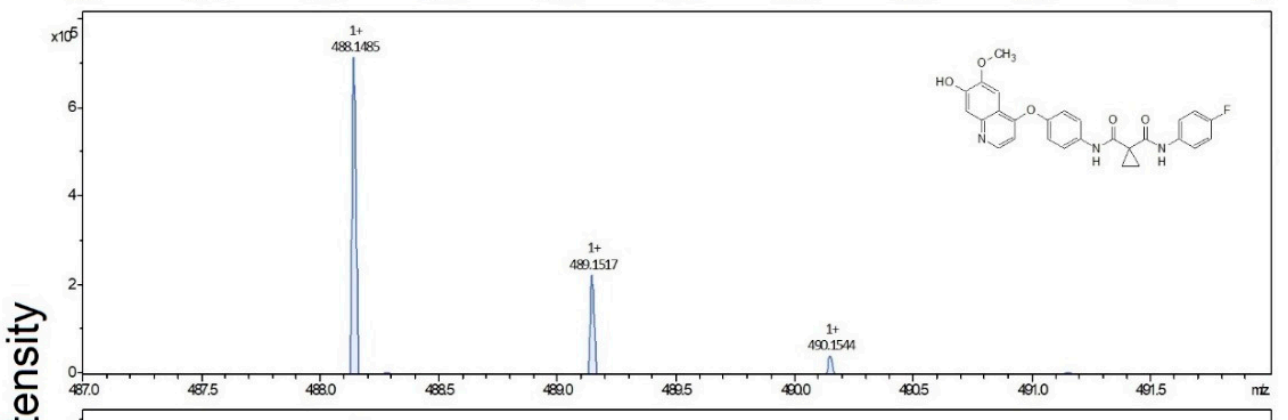

D

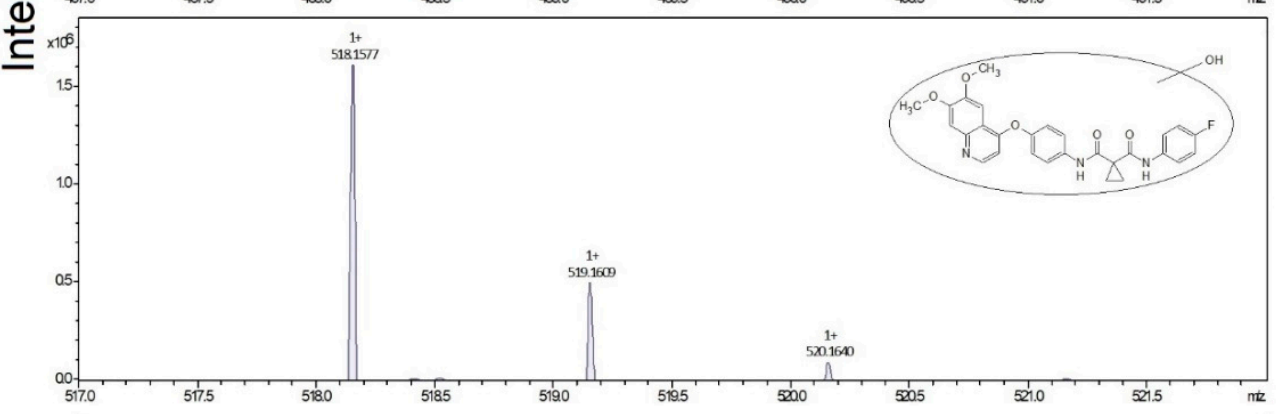

$E$

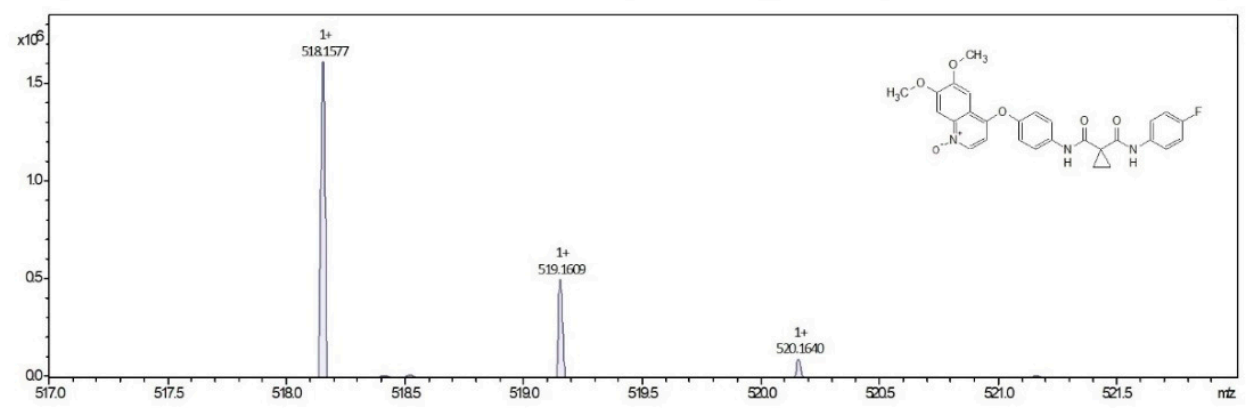

Figure 1. Representative HPLC chromatogram of cabozantinib metabolites formed in the presence of NADPH (blue line) and without NADPH (control, black line). M1-monohydroxy cabozantinib; M2desmethyl cabozantinib; M3 - cabozantinib N-oxide (A). Detailed mass spectrum and structure (insert) of cabozantinib (B), desmethyl cabozantinib (C), monohydroxy cabozantinib (D) and cabozantinib $N$-oxide (E). 
Table 1. CYP- and FMO-dependent catalytic activities and amounts of cabozantinib metabolites in samples of human liver microsomes.

\begin{tabular}{|c|c|c|c|c|c|c|c|c|c|c|c|c|c|c|c|c|c|}
\hline & Total CYPs a & POR $^{b}$ & Cyt b $b^{c}$ & CYP1A2 $^{d}$ & CYP2A6 $^{d}$ & CYP2B6 $^{\mathrm{d}}$ & CYP2C8 ${ }^{d}$ & CYP2C9 ${ }^{d}$ & $\mathrm{CYP}^{2 C 19^{\mathrm{d}}}$ & CYP2D6 $^{\mathrm{d}}$ & CYP2E1 ${ }^{d}$ & CYP3A4 ${ }^{d}$ & CYP4A11 $^{\mathrm{d}}$ & FMO $^{d}$ & M1 ${ }^{\mathrm{e}}$ & $\mathrm{M} 2 \mathrm{e}^{\mathrm{e}}$ & M3 ${ }^{\mathrm{e}}$ \\
\hline HG03 & 290 & 450 & 380 & 170 & 2000 & 51 & 200 & 1700 & 44 & 110 & 1800 & 6100 & 1600 & & 0.287 & 0.335 & 1.672 \\
\hline HG103 & 340 & 210 & 790 & 310 & 440 & 7.2 & 39 & 2300 & 23 & 65 & 1100 & 2200 & 1600 & 1400 & 0.109 & 0.144 & 0.644 \\
\hline HG24 & 260 & 260 & 550 & 1700 & 1500 & 35 & 190 & 3000 & 41 & - & 2300 & 4000 & 1800 & 1500 & 0.132 & 0.149 & 0.752 \\
\hline HG32 & 170 & 330 & 580 & 730 & 520 & 0.68 & 20 & 450 & 4.8 & 46 & 1200 & 2000 & 680 & 920 & 0.208 & 0.185 & 1.338 \\
\hline HG42 & 670 & 510 & 500 & 700 & 2200 & 150 & 480 & 1600 & 7.4 & 95 & 1600 & 15,000 & 1400 & 2000 & 0.301 & 0.329 & 1.609 \\
\hline HG43 & 270 & 210 & 640 & 580 & 770 & 14 & 25 & 1800 & 440 & 4 & 780 & 4600 & 1800 & 920 & 0.755 & 0.625 & 3.491 \\
\hline HG74 & 220 & 200 & 600 & 520 & 360 & 13 & 130 & 2100 & 55 & 120 & 1400 & 2700 & 1300 & 1200 & 0.148 & 0.256 & 1.106 \\
\hline HG93 & 430 & 320 & 450 & 691 & 350 & 43 & 270 & 2200 & 75 & 49 & 2800 & 2800 & 1800 & 3500 & 0.292 & 0.371 & 1.935 \\
\hline HK23 & 380 & 380 & 700 & 960 & 1100 & 24 & 160 & 2100 & 110 & 140 & 2100 & 6800 & 780 & 2500 & 0.094 & 0.130 & 0.607 \\
\hline HK27 & 300 & 450 & 730 & 1320 & 1320 & 31 & 180 & 480 & 460 & 130 & 3000 & 4910 & 1110 & 2230 & 0.273 & 0.467 & 2.228 \\
\hline HK31 & 580 & 540 & 770 & 1220 & 2160 & 8.1 & 130 & 1690 & 172 & 3.4 & 1660 & 8210 & 2010 & 3020 & 0.218 & 0.377 & 1.537 \\
\hline HK34 & 500 & 460 & 890 & 1000 & 1500 & 39 & 220 & 1900 & 45 & 100 & 6000 & 5200 & 1100 & 2700 & 0.209 & 0.305 & 1.359 \\
\hline
\end{tabular}

${ }^{\text {a }}$ Total CYP in pmol CYP/mg protein; ${ }^{b}$ POR activity of cytochrome c reductase (pmol/mg protein); ${ }^{\mathrm{c}} \mathrm{Cyt} \mathrm{b}_{5}$ was determined spectrophotometrically (pmol/mg protein); ${ }^{\mathrm{d}} \mathrm{CYP}-$ and

FMO-specific activity in pmol product/(mg protein $\times$ min): Phenacetin-O-deethylase (CYP1A2), Coumarine-7-hydroxylase (CYP2A6), (S)-Mephenytoin-N-demethylase (CYP2B6), Paclitaxel-6 $\alpha$-hydroxylase (CYP2C8), Diclofenac-4'-hydroxylase (CYP2C9), (S)-Mephenytoin-4'-hydroxylase (CYP2C19), Buferalol-1'-hydroxylase (CYP2D6), Chlorzoxazone-6-hydroxylase

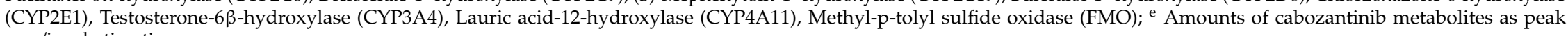
area/incubation time.

Table 2. Correlation coefficient (r) among CYP- and FMO-linked catalytic activity and amounts of cabozantinib metabolites formed in microsomes.

\begin{tabular}{ccccccccccccc}
\hline & Total CYPs & CYP1A2 & CYP2A6 & CYP2B6 & CYP2C8 & CYP2C9 & CYP2C19 & CYP2D6 & CYP2E1 & CYP3A4 & CYP4A11 & FMO \\
\hline M1 & $0.705^{*}$ & 0.104 & $0.607^{*}$ & $0.886^{* * *}$ & $0.785^{* *}$ & 0.142 & -0.119 & 0.028 & -0.065 & $0.918^{* * *}$ & 0.163 & 0.137 \\
M2 & $0.794^{* *}$ & 0.280 & $0.841^{* * *}$ & $0.695^{*}$ & $0.654^{*}$ & 0.086 & 0.033 & -0.015 & 0.140 & $0.935^{* * *}$ & 0.193 & 0.315 \\
M3 & $0.811^{* *}$ & 0.216 & $0.728^{* *}$ & $0.776^{* *}$ & $0.737^{* *}$ & 0.130 & -0.021 & -0.043 & 0.030 & $0.947^{* * *}$ & 0.223 & 0.341 \\
\hline
\end{tabular}

${ }^{*} p<0.05 ;{ }^{* *} p<0.01 ;{ }^{* * *} p<0.001$ 


\subsection{The Effect of CYP Enzyme Inhibitors on Cabozantinib Oxidation in Human Liver Microsomes}

The importance of CYP3A4 in cabozantinib oxidation was confirmed by inhibition studies with human pooled liver microsomes from 21 donors. CYP-specific inhibitors $\alpha$-Naphthoflavone ( $\alpha$-NF, CYP1A), sulfaphenazole (CYP2C) and diethyldithiocarbamate (DDTC, CYP2A and CYP2E1) were inefficient in affecting the cabozantinib oxidation. Quinidine (inhibiting CYP2D) was able to inhibit formation of metabolites; however, $\mathrm{IC}_{50}$ was not attained. Thus, only inhibitors of CYP3A, namely ketoconazole and CYP3cide, were efficient in inhibiting the oxidation of cabozantinib. Both inhibitors were so efficient that, even in the lowest concentration, the formation of metabolites was inhibited by more than $50 \%$, so the values of $\mathrm{IC}_{50}$ are $<0.01 \mu \mathrm{M}$. The only exception was monohydroxy cabozantinib, which exhibited $\mathrm{IC}_{50}$ of $1.12 \mu \mathrm{M}$ for CYP3cide. Due to the higher efficiency of ketoconazole than CYP3cide, it is possible to suppose an oxidative role not only of CYP3A4 but also of CYP3A5 during cabozantinib oxidation in human liver microsomes. However, the role of CYP3A5 in this phenomenon seems to be minor in comparison to CYP3A4.

\subsection{Oxidation of Cabozantinib by Recombinant Human Cytochromes P450}

The use of recombinant CYP enzymes expressed in Supersomes ${ }^{\mathrm{TM}}$ was another approach to examine the ability of individual human CYP enzymes to oxidize cabozantinib. Of several tested CYPs, four cytochromes P450 were capable of oxidizing cabozantinib under the experimental conditions (Figure 2). CYP3A4, the most prominent enzyme oxidizing cabozantinib, generated three metabolites. Cyt $b_{5}$, the heme protein participating in several functions of the CYP-mono-oxygenase system [21,28-32], exhibits a stimulating effect on all three metabolites (Figure 2). The use of Supersomes ${ }^{\mathrm{TM}}$ with co-expression of cyt $b_{5}$ and CYP3A4 increased cabozantinib oxidation more than 2.9-fold. The greatest stimulatory effect of cyt $b_{5}$ was found in the formation of cabozantinib $N$-oxide (4.6-fold; $\left.p<0.001\right)$. Cyt $b_{5}$ also stimulates cabozantinib oxidation by CYP3A5. Thus, desmethyl cabozantinib was detected only in its presence (Figure 2). CYP1A1 and CYP1B1 each generate one metabolite, and their activity was not influenced by $c y t b_{5}$. CYP1A1 formed monohydroxy cabozantinib, while desmethyl cabozantinib was attributed to CYP1B1 (Figure 2). The proposed scheme of cabozantinib oxidation by human recombinant CYPs is shown in Figure 3.

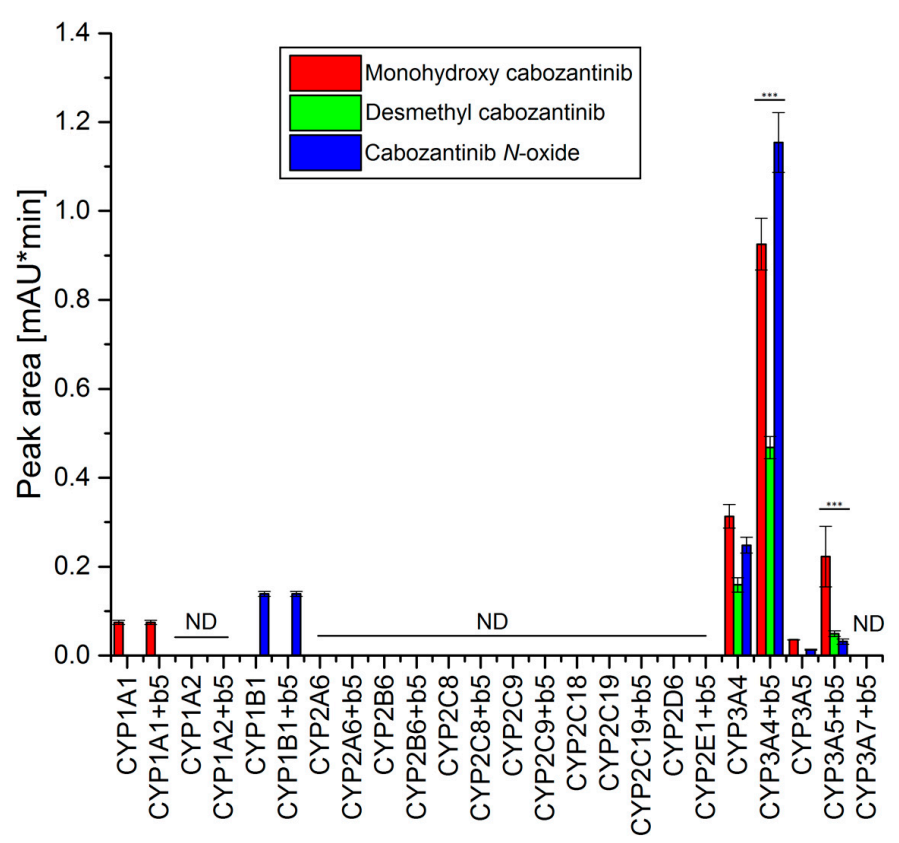

Figure 2. Oxidation of cabozantinib by human recombinant CYPs. Value represents mean $\pm \mathrm{SD}$ of three independent in vitro incubations $(n=3)$. ${ }^{* * *} p<0.001$ significant differences between the formation of individual metabolites by CYP enzymes with and without cytochrome $b_{5}\left(b_{5}\right)$. ND—not detected. 


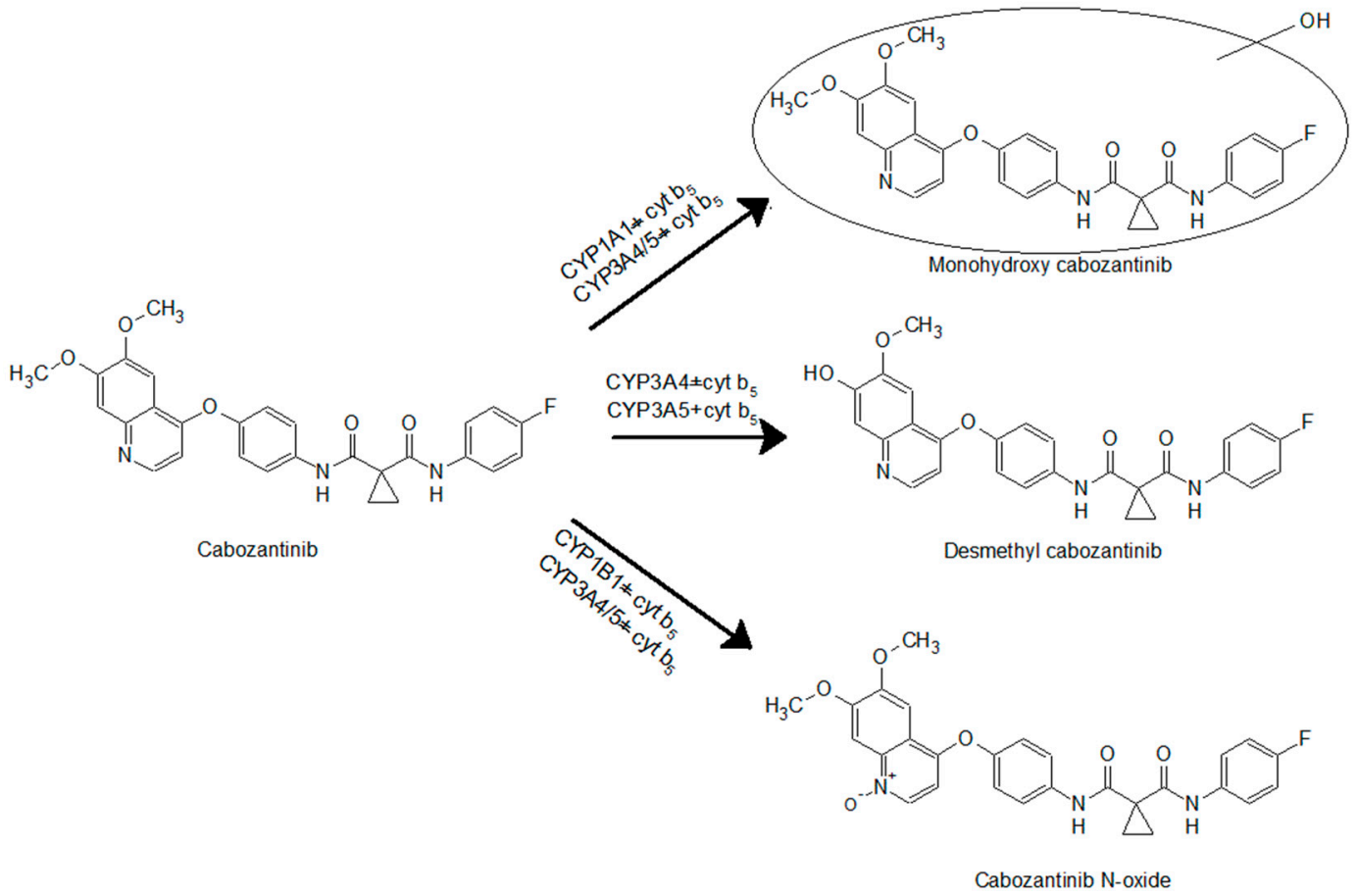

Figure 3. Cabozantinib oxidation by cytochrome P450s.

Based on the results assigning the velocities of cabozantinib oxidation to individual metabolites in experimental systems containing recombinant CYP enzymes in Supersomes ${ }^{\mathrm{TM}}$ (Figure 2) and the relative amounts of CYP enzymes expressed in human liver [25-27], the contributions of individual CYPs to these reactions in human livers were evaluated. For these calculations, we took the presence of cytochrome $b_{5}$ into account. The highest contribution to formations of all three metabolites was attributed to CYP3A4. Other CYPs contribute less than 3\% to the formation of monohydroxy cabozantinib and even less than $1 \%$ to the formation of desmethyl cabozantinib and cabozantinib $\mathrm{N}$-oxide.

Based on the obtained results, it is clear that cabozantinib is primarily oxidized by CYP3A4. Therefore we further investigated the kinetics of the CYP3A4-mediated cabozantinib oxidation (Figure 4 and Table 3). The presence and absence of cyt $b_{5}$ was considered. In the case of CYP3A4, the metabolites desmethyl cabozantinib and cabozantinib $N$-oxide exhibit hyperbolic kinetics (Figure 4B,C). The third metabolite, monohydroxy cabozantinib, is prone to substrate inhibition (Figure $4 \mathrm{~A}$ ). When cyt $\mathrm{b}_{5}$ is present in the incubations, the rate of cabozantinib oxidation and the kinetics are affected. The cyt $b_{5}$ increases the rate of cabozantinib oxidation, and a higher concentration of cabozantinib is required to attain half-maximal velocity. The $\mathrm{K}_{0.5}$ values triple with cytochrome $\mathrm{b}_{5}$, which indicates that allosteric effects may affect catalysis. The allosteric effects are also supported by the fact that the formation of monohydroxy cabozantinib exhibits hyperbolic kinetics, although without cyt $b_{5}$, it exhibits substrate inhibition (Figure $4 \mathrm{~A}, \mathrm{D}$ ). The formation of cabozantinib $\mathrm{N}$-oxide is also affected by cyt $b_{5}$ and is prone to substrate inhibition in its presence (Figure $4 \mathrm{~F}$ ). Desmethyl cabozantinib exhibits hyperbolic kinetics regardless of cytochrome $b_{5}$ (Figure $4 B, E$ ). Thus, cyt $b_{5}$ not only stimulates the cabozantinib oxidation by CYP3A4 but also affects the affinity of this enzyme.

\subsection{Oxidation of Cabozantinib by Recombinant Human Flavin-Containing Mono-oxygenases and Aldehyde Oxidase}

The potential of aldehyde oxidase and flavin-containing mono-oxygenases to oxidize cabozantinib was studied with human recombinant enzymes. Aldehyde oxidase and all three tested flavin-containing mono-oxygenases (FMO 1, 3 and 5) were ineffective in cabozantinib oxidation (data not shown). 
CYP3A4
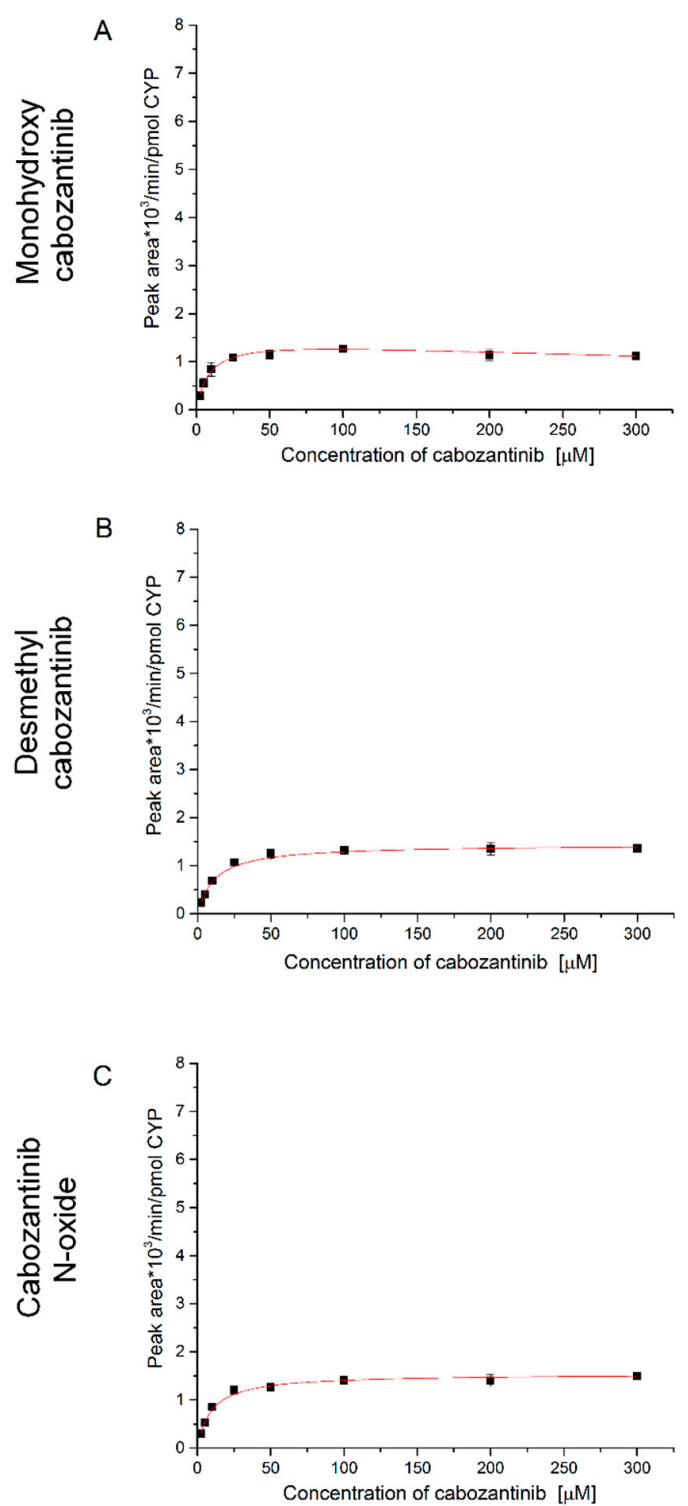

CYP3A4+cyt $b_{5}$

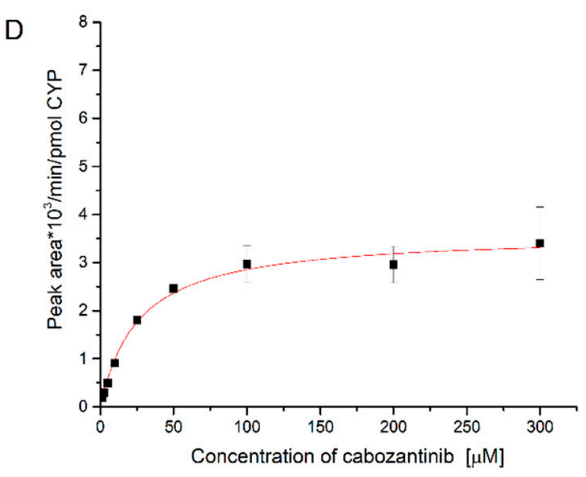

E
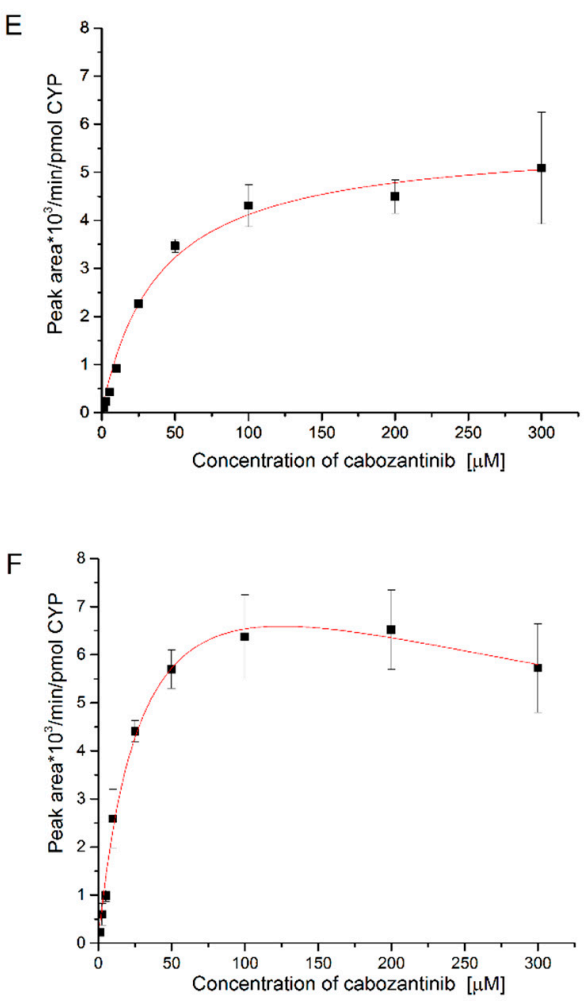

Figure 4. Enzyme kinetics of cabozantinib oxidation by CYP3A4 (A-C) and CYP3A4 in the presence of cytochrome $b_{5}(\mathbf{D}-\mathbf{F})$ to monohydroxy cabozantinib $(\mathbf{A}, \mathbf{D})$, desmethyl cabozantinib (B,E) and cabozantinib $\mathrm{N}$-oxide $(\mathbf{C}, \mathbf{F})$. Values represent means $\pm \mathrm{SD}$ of three independent in vitro incubations $(n=3)$.

Table 3. The characteristics of the kinetics of cabozantinib oxidation by CYP3A4 and this enzyme in the presence of cyt $b_{5}$.

\begin{tabular}{ccccc}
\hline \multirow{2}{*}{ Enzyme } & \multirow{2}{*}{ Metabolite } & \multicolumn{3}{c}{ Kinetic Characteristics $^{\mathbf{a}}$} \\
\cline { 3 - 5 } & & $\mathbf{V}_{\mathbf{M a x}}($ peak area/min/nmol CYP) & $\mathbf{K}_{\mathbf{0 . 5}}(\boldsymbol{\mu M})$ & $\mathbf{K}_{\mathbf{i}}(\boldsymbol{\mu} \mathbf{M})$ \\
\hline \multirow{2}{*}{ CYP3A4 } & Monohydroxy cabozantinib & $1.50 \pm 0.05$ & $8.98 \pm 1.04$ & $947.87 \pm 202.96$ \\
\cline { 2 - 5 } & Desmethyl cabozantinib & $1.44 \pm 0.03$ & $11.69 \pm 1.00$ & NA \\
\cline { 2 - 5 } & Cabozantinib N-oxide & $1.54 \pm 0.04$ & $9.56 \pm 0.69$ & NA \\
\hline \multirow{2}{*}{ CYP3A4 + cyt b5 } & Monohydroxy cabozantinib & $3.60 \pm 0.11$ & $26.00 \pm 2.92$ & NA \\
\cline { 2 - 5 } & Desmethyl cabozantinib & $5.70 \pm 0.24$ & $38.53 \pm 5.35$ & NA \\
\cline { 2 - 5 } & Cabozantinib N-oxide & $9.96 \pm 0.92$ & $32.03 \pm 5.68$ & $490.22 \pm 139.7$ \\
\hline
\end{tabular}

${ }^{a}$ Values represent means \pm SD of three independent in vitro incubations $(n=3)$. NA-not applicable. 


\section{Discussion}

In the present study, we utilized several approaches to identify individual CYP enzymes oxidizing cabozantinib. Ketoconazole, an inhibitor of CYP3A [33,34], and CYP3cide, a specific inhibitor of CYP3A4 [35], were highly efficient in the inhibition of cabozantinib oxidation. Inhibitors of other CYPs, namely $\alpha-\mathrm{NF}$, sulfaphenazole and DDTC, showed no inhibitory effects or, in the case of quinidine, the value of $\mathrm{IC}_{50}$ was not reached. However, it is important to point out that results found with inhibitors are sometimes difficult to interpret because inhibitors can act more efficiently with one enzyme substrate than another and may influence multiple forms of cytochrome P450. Therefore, we employed additional experimental approaches: (i) correlation analysis between the CYP- and FMO-catalytic activities in each microsomal sample with the amounts of individual metabolites formed by the same microsomes; and (ii) analysis of the oxidation of cabozantinib by human recombinant CYPs, FMOs and AO. In the human hepatic microsomal systems, CYP3A4 was determined as the most important enzyme in the formations of cabozantinib metabolites based on correlation analysis. Human recombinant CYP3A4 expressed in Supersomes ${ }^{\mathrm{TM}}$ was also the most effective enzyme responsible for the formation of cabozantinib metabolites. The significant role of CYP3A4 in the oxidation of cabozantinib was proposed and indicated by others [36,37]. Many other TKIs are also known substrates of CYP3A4 [31,38-41]. All these data, and the fact that CYP3A4 is the predominant form of cytochrome P450 in human liver [25,42], indicate the privileged role of this enzyme in the oxidation of TKIs including cabozantinib.

The oxidation of cabozantinib by CYP3A4 is stimulated by cytochrome $b_{5}$. The stimulatory effect of cyt $b_{5}$ on CYP3A4-mediated oxidation is known for endogenous $[28,43]$ as well as exogenous substrates [30,43-46], including TKIs [31]. However, the catalytic activity of CYP3A4 shows large interindividual variability depending on many factors such as modulation of CYP3A4 expression by xenobiotics and the diet or genetic polymorphism. Polymorphism in CYP3A4 genes has a great impact on enzymatic activities, thereby influencing the metabolism and elimination of drugs [42,47]. The effect of CYP3A4 polymorphism on the oxidation of cabozantinib to cabozantinib $\mathrm{N}$-oxide was described recently [37]. Cytochrome $b_{5}$ also exhibits interindividual variability. Protein and mRNA contents show variations with 11- and 6-fold range, respectively. However, the content of cyt b5 mRNA does not strongly correlate with that of $c y t b_{5}$ protein [48]. Other studies also reported variability in cyt $b_{5}$ protein and mRNA [49,50]. Correlation between cyt $b_{5}$ and CYP3A4 activity was found [48]. Further, single nucleotide polymorphisms in cyt $b_{5}$ were associated with very low activity and protein expression [51]. All these factors can contribute to interindividual differences in the CYP3A4-mediated pharmacokinetic profiles of cabozantinib.

Cabozantinib showed generally broader and more potent kinase inhibition compared to its metabolites. Estimated IC 50 of cabozantinib for MET, RET and VEGFR2 are 2, 8 and $14 \mathrm{nM}$, respectively. Cabozantinib $\mathrm{N}$-oxide activities against these kinases are 190, >1000 and $140 \mathrm{nM}$, respectively [18]. Effectiveness of cabozantinib might thus be significantly reduced by CYP3A4-mediated oxidation in enterocytes and liver cells. This can lead to different anticancer activity and/or adverse effects after cabozantinib treatment. Cabozantinib could cause many side effects, which require subsequent dose modification [52]. To better understand the forming of metabolites, kinetics of cabozantinib oxidation by CYP3A4, the most efficient enzyme oxidizing cabozantinib, was analyzed. All metabolites formed by CYP3A4 exhibit $K_{0.5}$ from 9 to $12 \mu \mathrm{M}$ and very similar $\mathrm{V}_{\mathrm{Max}}$. Addition of cyt $\mathrm{b}_{5}$ into the incubation mixture causes an increase in these parameters. Particularly, $\mathrm{K}_{0.5}$ is approximately three times higher in the presence of cyt $b_{5}$. Nevertheless, the change of $V_{\text {Max }}$ is up to 6.5-fold higher. These results indicate that cyt $b_{5}$ affects the affinity of CYP3A4. Further evidence for the influencing of affinity comes from changing hyperbolic kinetics into substrate inhibition in the case of cabozantinib $\mathrm{N}$-oxide or vice versa in the case of desmethyl cabozantinib. Substrate inhibition for the formation of cabozantinib $\mathrm{N}$-oxide was recently observed with many isoforms of CYP3A4 in the presence of cyt $b_{5}$ [37]. Another previously published study claimed that cabozantinib is not the only substrate of CYP3A4 but also a direct inhibitor of this enzyme with a $\mathrm{IC}_{50}$ value $272 \mu \mathrm{M}$ (midazolam 1'-hydroxylase), while cabozantinib did not inhibit CYP3A4-mediated testosterone $6 \beta$-hydroxylation [18]. Our results confirm the ability of cabozantinib 
to inhibit CYP3A4; however, the $\mathrm{IC}_{50}$ is higher than the value presented in the above-mentioned study. With respect to plasma concentration of cabozantinib in patients, it is unexpected for CYP3A4 inhibition by cabozantinib to be observed. Plasma concentration of cabozantinib in metastatic renal cell carcinoma patients has a mean of $973 \pm 501 \mathrm{ng} / \mathrm{mL}$. The range of measured concentrations was 203 to $2100 \mathrm{ng} / \mathrm{mL}$ [53]. In patients with thyroid cancers, a therapeutic window between $500-1500 \mathrm{ng} / \mathrm{mL}$ has been proposed for cabozantinib trough levels to ensure an acceptable efficacy/toxicity balance [54]. Metabolites formed by CYP3A4 exhibit $\mathrm{K}_{0.5}$ near $10 \mu \mathrm{M}$, thus only at three times higher concentration than is observed in patients. Because of the lower efficiency of cabozantinib metabolites, extensive metabolizers may require higher doses, and inducers and inhibitors of CYP3A4 should be avoided or dose modifications should be considered during cabozantinib treatment.

\section{Conclusions}

Cabozantinib $\mathrm{N}$-oxide, desmethyl cabozantinib and monohydroxy cabozantinib were identified as major oxidation products of cabozantinib, the drug used for the treatment of metastatic medullary thyroid cancer and advanced renal cell carcinoma. CYP3A4 was identified as a prominent cytochrome P450 forming cabozantinib metabolites, which is responsible for nearly all cabozantinib oxidation in the human liver. The oxidation of cabozantinib by CYP3A4 is stimulated by cyt $\mathrm{b}_{5}$ and may be prone to substrate inhibition. Therefore, the presence of CYP3A4 modulators should be considered during cabozantinib treatment.

Author Contributions: Conception, design, interpretation of the data, HPLC of metabolites, enzyme kinetics measurement: R.I. Preparation of microsomes of animal models, HPLC of metabolites, enzyme kinetics measurement: K.V. Characterization of metabolites by mass spectrometry: P.P. Design: Z.H., R.I. Drafting of the article: R.I. Critical revision of the article for important intellectual content: R.I., Z.H., P.H. All authors have read and agreed to the published version of the manuscript.

Funding: The work was supported by Grant Agency of the Czech Republic (grant 18-10251S).

Conflicts of Interest: The authors declare no conflict of interest.

$\begin{array}{ll}\text { Abbreviations } \\ \alpha-\mathrm{NF} & \alpha \text {-Naphthoflavone } \\ \mathrm{AO} & \text { Aldehyde oxidase } \\ \mathrm{CYP} & \text { Cytochrome P450 } \\ \text { Cyt } b_{5} & \text { Cytochrome } b_{5} \\ \text { DDTC } & \text { Diethyldithiocarbamate } \\ \text { FMO } & \text { Flavin-containing mono-oxygenase } \\ \text { HPLC } & \text { High-performance liquid chromatography } \\ \mathrm{M}_{1-3} & \text { Cabozantinib metabolites } \\ \text { MET } & \text { Hepatocyte growth factor receptor } \\ \text { POR } & \text { NADPH:CYP oxidoreductase } \\ \text { RET } & \text { Rearranged during transfection receptor } \\ \text { TKI } & \text { Tyrosine kinase inhibitor } \\ \text { VEGFR } & \text { Vascular endothelial growth factor receptor }\end{array}$

\section{References}

1. Wilkinson, G.R. Drug metabolism and variability among patients in drug response. N. Engl. J. Med. 2005, 352, 2211-2221. [CrossRef] [PubMed]

2. Fujita, K. Cytochrome P450 and anticancer drugs. Curr. Drug Metab. 2006, 7, 23-37. [CrossRef] [PubMed]

3. Kurzrock, R.; Sherman, S.I.; Ball, D.W.; Forastiere, A.A.; Cohen, R.B.; Mehra, R.; Pfister, D.G.; Cohen, E.E.W.; Janisch, L.; Nauling, F.; et al. Activity of XL184 (Cabozantinib), an oral tyrosine kinase inhibitor, in patients with medullary thyroid cancer. J. Clin. Oncol. 2011, 29, 2660-2666. [CrossRef] [PubMed] 
4. Tolaney, S.M.; Nechushtan, H.; Ron, I.; Schöffski, P.; Awada, A.; Yasenchak, C.A.; Laird, A.D.; O'Keeffe, B.; Shapiro, G.I.; Winer, E.R. Cabozantinib for metastatic breast carcinoma: Results of a phase II placebo-controlled randomized discontinuation study. Breast Cancer Res. Treat. 2016, 160, 305-312. [CrossRef] [PubMed]

5. Tolaney, S.M.; Ziehr, D.R.; Guo, H.; Ng, M.R.; Barry, W.T.; Higgins, M.J.; Isakoff, S.J.; Brock, J.E.; Ivanova, E.V.; Paweletz, C.P.; et al. Phase II and biomarker study of cabozantinib in metastatic triple-negative breast cancer patients. Oncologist 2017, 22, 25-32. [CrossRef]

6. Kelley, R.K.; Verslype, C.; Cohn, A.L.; Yang, T.S.; Su, W.C.; Burris, H.; Braiteh, F.; Vogelzang, N.; Spira, A.; Foster, P.; et al. Cabozantinib in hepatocellular carcinoma: Results of a phase 2 placebo-controlled randomized discontinuation study. Ann. Oncol. 2017, 28, 528-534. [CrossRef]

7. Abou-Alfa, G.K.; Meyer, T.; Cheng, A.L.; El-Khoueiry, A.B.; Rimassa, L.; Ryoo, B.Y.; Cicin, I.; Merle, P.; Chen, Y.H.; Park, J.W.; et al. Cabozantinib in patients with advanced and progressing hepatocellular carcinoma. N. Engl. J. Med. 2018, 379, 54-63. [CrossRef]

8. Drilon, A.; Wang, L.; Hasanovic, A.; Suehara, Y.; Lipson, D.; Stephens, P.; Roos, J.; Miller, V.; Ginsberg, M.; Zakowski, M.F.; et al. Response to Cabozantinib in patients with RET fusion-positive lung adenocarcinomas. Cancer Discov. 2013, 3, 630-635. [CrossRef]

9. Nokihara, H.; Nishio, M.; Yamamoto, N.; Fujiwara, Y.; Horinouchi, H.; Kanda, S.; Horiike, A.; Ohyanagi, F.; Yanagitani, N.; Nguyen, L.; et al. Phase 1 Study of Cabozantinib in Japanese Patients with Expansion Cohorts in Non-Small-Cell Lung Cancer. Clin. Lung Cancer 2019, 20, e317-e328. [CrossRef]

10. Smith, D.C.; Smith, M.R.; Sweeney, C.; Elfiky, A.A.; Logothetis, C.; Corn, P.G.; Vogelzang, N.J.; Small, E.J.; Harzstark, A.L.; Gordon, S.; et al. Cabozantinib in patients with advanced prostate cancer: Results of a phase II randomized discontinuation trial. J. Clin. Oncol. 2013, 31, 412-419. [CrossRef]

11. Dai, J.; Zhang, H.; Karatsinides, A.; Keller, J.M.; Kozloff, K.M.; Aftab, D.T.; Schimmoller, F.; Keller, E.T. Cabozantinib inhibits prostate cancer growth and prevents tumor-induced bone lesions. Clin. Cancer Res. 2014, 20, 617-630. [CrossRef] [PubMed]

12. Choueiri, T.K.; Escudier, B.; Powles, T.; Mainwaring, P.N.; Rini, B.I.; Donskov, F.; Hammers, H.; Hutson, T.E.; Lee, J.L.; Peltola, K.; et al. Cabozantinib versus everolimus in advanced renal-cell carcinoma. N. Engl. J. Med. 2015, 373, 1814-1823. [CrossRef]

13. Choueiri, T.K.; Escudier, B.; Powles, T.; Tannir, N.M.; Mainwaring, P.N.; Rini, B.I.; Hammers, H.J.; Donskov, F.; Roth, B.J.; Peltola, K.; et al. Cabozantinib versus everolimus in advanced renal cell carcinoma (METEOR): Final results from a randomised, open-label, phase 3 trial. Lancet Oncol. 2016, 17, 917-927. [CrossRef]

14. Hage, C.; Rausch, V.; Giese, N.; Giese, T.; Schönsiegel, F.; Labsch, S.; Nwaeburu, C.; Mattern, J.; Gladkich, J.; Herr, I. The novel c-Met inhibitor cabozantinib overcomes gemcitabine resistance and stem cell signaling in pancreatic cancer. Cell Death Dis. 2013, 4, e627. [CrossRef] [PubMed]

15. Yakes, F.M.; Chen, J.; Tan, J.; Yamaguchi, K.; Shi, Y.; Yu, P.; Qian, F.; Chu, F.; Bentzien, F.; Cancilla, B.; et al. Cabozantinib (XL184), a novel MET and VEGFR2 inhibitor, simultaneously suppresses metastasis, angiogenesis, and tumor growth. Mol. Cancer Ther. 2011, 10, 2298-2308. [CrossRef]

16. Bentzien, F.; Zuzow, M.; Heald, N.; Gibson, A.; Shi, Y.; Goon, L.; Yu, P.; Engst, S.; Zhang, W.; Huang, D.; et al. In vitro and in vivo activity of cabozantinib (XL184), an inhibitor of RET, MET, and VEGFR2, in a model of medullary thyroid cancer. Thyroid 2013, 23, 1569-1577. [CrossRef]

17. Xiang, Q.; Chen, W.; Ren, M.; Wang, J.; Zhang, H.; Deng, D.Y.B.; Zhang, L.; Shang, C.; Chen, Y. Cabozantinib suppresses tumor growth and metastasis in hepatocellular carcinoma by a dual blockade of VEGFR2 and MET. Clin. Cancer Res. 2014, 20, 2959-2970. [CrossRef]

18. Lacy, S.; Hsu, B.; Miles, D.; Aftab, D.; Wang, R.; Nguyen, L. Metabolism and disposition of cabozantinib in healthy male volunteers and pharmacologic characterization of its major metabolites. Drug Metab. Dispos. 2015, 43, 1190-1207. [CrossRef]

19. Gerendash, B.S.; Creel, P.A. Practical management of adverse events associated with cabozantinib treatment in patients with renal-cell carcinoma. OncoTargets Ther. 2017, 10, 5053. [CrossRef]

20. FDA Center for Drug Evaluation and Research. Cabometyx Full Prescribing Information. Available online: https://www.accessdata.fda.gov/drugsatfda_docs/label/2016/208692s000lbl.pdf (accessed on 20 September 2020).

21. Stiborová, M.; Indra, R.; Mizerovská, M.; Frei, E.; Schmeiser, H.H.; Kopka, K.; Philips, D.H.; Arlt, V.M. $\mathrm{NADH}: C y$ tochrome $\mathrm{b}_{5}$ reductase and cytochrome $b_{5}$ can act as sole electron donors to human cytochrome P450 1A1-mediated oxidation and DNA adduct formation by benzo[a]pyrene. Chem. Res. Toxicol. 2016, 29, 1325-1334. [CrossRef] 
22. Kotrbova, V.; Mrazova, B.; Moserova, M.; Martinek, V.; Hodek, P.; Hudecek, J.; Frei, E.; Stiborova, M. Cytochrome $b_{5}$ shifts oxidation of the anticancer drug ellipticine by cytochromes P450 1A1 and 1A2 from its detoxication to activation, thereby modulating its pharmacological efficacy. Biochem. Pharmacol. 2011, 82, 669-680. [CrossRef] [PubMed]

23. Šulc, M.; Indra, R.; Moserová, M.; Schmeiser, H.H.; Frei, E.; Arlt, V.M.; Stiborová, M. The impact of individual cytochrome P450 enzymes on oxidative metabolism of benzo[a]pyrene in human livers. Environ. Mol. Mutagen. 2016, 57, 229-235. [CrossRef] [PubMed]

24. Stiborová, M.; Borek-Dohalska, L.; Aimova, D.; Kotrbova, V.; Kukackova, K.; Janouchova, K.; Rupertova, M.; Ryslava, H.; Hudecek, J.; Frei, E. Oxidation pattern of the anticancer drug ellipticine by hepatic microsomesSimilarity between human and rat systems. Gen. Physiol. Biophys. 2006, 25, 245-261. [PubMed]

25. Rendic, S.; DiCarlo, F.J. Human cytochrome P450 enzymes: A status report summarizing their reactions, substrates, inducers, and inhibitors. Drug Metab. Rev. 1997, 29, 413-480. [CrossRef] [PubMed]

26. Stiborová, M.; Martínek, V.; Rýdlová, H.; Hodek, P.; Frei, E. Sudan I is a potential carcinogen for humans: Evidence for its metabolic activation and detoxication by human recombinant cytochrome P450 1A1 and liver microsomes. Cancer Res. 2002, 62, 5678-5684. [PubMed]

27. Stiborová, M.; Martínek, V.; Rýdlová, H.; Koblas, T.; Hodek, P. Expression of cytochrome P450 1 A1 and its contribution to oxidation of a potential human carcinogen 1-phenylazo-2-naphthol (Sudan I) in human livers. Cancer Lett. 2005, 220, 145-154. [CrossRef] [PubMed]

28. Yamazaki, H.; Nakano, M.; Omak, Y.; Ueng, Y.F.; Guengerich, F.P.; Shimada, T. Roles of cytochrome $b_{5}$ in the oxidation of testosterone and nifedipine by recombinant cytochrome P450 3A4 and by human liver microsomes. Arch. Biochem. Biophys. 1996, 325, 174-182. [CrossRef] [PubMed]

29. Porter, T.D. The roles of cytochrome $b_{5}$ in cytochrome P450 reactions. J. Biochem. Mol. Toxicol. 2002, 16, 311-316. [CrossRef]

30. Stiborová, M.; Indra, R.; Frei, E.; Kopečková, K.; Schmeiser, H.H.; Eckschlager, T.; Adam, V.; Heger, Z.; Arlt, V.M.; Martínek, V. Cytochrome $b_{5}$ plays a dual role in the reaction cycle of cytochrome P450 3A4 during oxidation of the anticancer drug ellipticine. Monatsh. Chem. 2017, 148, 1983-1991. [CrossRef]

31. Indra, R.; Pompach, P.; Martínek, V.; Takácsová, P.; Vavrová, K.; Heger, Z.; Adam, V.; Eckschlager, T.; Kopečková, K.; Arlt, V.M.; et al. Identification of Human Enzymes Oxidizing the Anti-Thyroid-Cancer Drug Vandetanib and Explanation of the High Efficiency of Cytochrome P450 3A4 in its Oxidation. Int. J. Mol. Sci. 2019, 20, 3392. [CrossRef]

32. Schenkman, J.B.; Jansson, I. The many roles of cytochrome $b_{5}$. Pharmacol. Ther. 2003, 97, 139-152. [CrossRef]

33. Achira, M.; Ito, K.; Suzuki, H.; Sugiyama, Y. Comparative studies to determine the selective inhibitors for P-glycoprotein and cytochrome P 4503A4. AAPS Pharmsci. 1999, 1, 14-19. [CrossRef] [PubMed]

34. Greenblatt, D.J.; Zhao, Y.; Venkatakrishnan, K.; Duan, S.X.; Harmatz, J.S.; Parent, S.J.; Court, M.H.; von Moltke, L.L. Mechanism of cytochrome P450-3A inhibition by ketoconazole. J. Pharm. Pharmacol. 2011, 63, 214-221. [CrossRef] [PubMed]

35. Walsky, R.L.; Obach, R.S.; Hyland, R.; Kang, P.; Zhou, S.; West, M.; Geoghegan, K.F.; Helal, C.J.; Walker, G.S.; Goosen, T.C.; et al. Selective mechanism-based inactivation of CYP3A4 by CYP3cide (PF-04981517) and its utility as an in vitro tool for delineating the relative roles of CYP3A4 versus CYP3A5 in the metabolism of drugs. Drug Metab. Dispos. 2012, 40, 1686-1697. [CrossRef]

36. Nguyen, L.; Holland, J.; Miles, D.; Engel, C.; Benrimoh, N.; O’Reilly, T.; Lacy, S. Pharmacokinetic (PK) drug interaction studies of cabozantinib: Effect of CYP3A inducer rifampin and inhibitor ketoconazole on cabozantinib plasma PK and effect of cabozantinib on CYP2C8 probe substrate rosiglitazone plasma PK. J. Clin. Pharmacol. 2015, 55, 1012-1023. [CrossRef]

37. Lin, Q.M.; Li, Y.H.; Lu, X.R.; Wang, R.; Pang, N.H.; Xu, R.A.; Cai, J.P.; Hu, G.X. Characterization of Genetic Variation in CYP3A4 on the Metabolism of Cabozantinib in Vitro. Chem. Res. Toxicol. 2019, 32, 1583-1590. [CrossRef]

38. Li, J.; Zhao, M.; He, P.; Hidalgo, M.; Baker, S.D. Differential metabolism of gefitinib and erlotinib by human cytochrome P450 enzymes. Clin. Cancer Res. 2007, 13, 3731-3737. [CrossRef]

39. Van Erp, N.P.; Gelderblom, H.; Karlsson, M.O.; Li, J.; Zhao, M.; Ouwerkerk, J.; Nortier, J.W.; Guchelaar, H.J.; Baker, S.D.; Sparreboom, A. Influence of CYP3A4 inhibition on the steady-state pharmacokinetics of imatinib. Clin. Cancer Res. 2007, 13, 7394-7400. [CrossRef]

40. Kim, A.; Balis, F.M.; Widemann, B.C. Sorafenib and sunitinib. Oncologist 2009, 14, 800. [CrossRef] 
41. Jackson, K.D.; Durandis, R.; Vergne, M.J. Role of cytochrome P450 enzymes in the metabolic activation of tyrosine kinase inhibitors. Int. J. Mol. Sci. 2018, 19, 2367. [CrossRef]

42. Zanger, U.M.; Schwab, M. Cytochrome P450 enzymes in drug metabolism: Regulation of gene expression, enzyme activities, and impact of genetic variation. Pharmacol. Ther. 2013, 138, 103-141. [CrossRef] [PubMed]

43. Voice, M.W.; Zhang, Y.; Wolf, C.R.; Burchell, B.; Friedberg, T. Effects of Human Cytochrome b5on CYP3A4 Activity and Stability in Vivo. Arch. Biochem. Biophys. 1999, 366, 116-124. [CrossRef] [PubMed]

44. Stiborová, M.; Sejbal, J.; Bořek-Dohalská, L.; Aimová, D.; Poljaková, J.; Forsterová, K.; Rupertová, M.; Wiesner, J.; Hudeček, J.; Wiessler, M.; et al. The anticancer drug ellipticine forms covalent DNA adducts, mediated by human cytochromes P450, through metabolism to 13-hydroxyellipticine and ellipticine N2-oxide. Cancer Res. 2004, 64, 8374-8380. [CrossRef] [PubMed]

45. Jushchyshyn, M.I.; Hutzler, J.M.; Schrag, M.L.; Wienkers, L.C. Catalytic turnover of pyrene by CYP3A4: Evidence that cytochrome b5 directly induces positive cooperativity. Arch. Biochem. Biophys. 2005, 438, 21-28. [CrossRef] [PubMed]

46. Henderson, C.J.; McLaughlin, L.A.; Scheer, N.; Stanley, L.A.; Wolf, C.R. Cytochrome b5 is a major determinant of human cytochrome P450 CYP2D6 and CYP3A4 activity in vivo. Mol. Pharmacol. 2015, 87, 733-739. [CrossRef] [PubMed]

47. Ingelman-Sundberg, M.; Sim, S.C.; Gomez, A.; Rodriguez-Antona, C. Influence of cytochrome P450 polymorphisms on drug therapies: Pharmacogenetic, pharmacoepigenetic and clinical aspects. Pharmacol. Therap. 2007, 116, 496-526. [CrossRef] [PubMed]

48. Yoo, S.E.; Yi, M.; Kim, W.Y.; Cho, S.A.; Lee, S.S.; Lee, S.J.; Shin, J.G. Influences of cytochrome b5 expression and its genetic variant on the activity of CYP2C9, CYP2C19 and CYP3A4. Drug Metab. Pharmacokinet. 2019, 34, 201-208. [CrossRef]

49. Zhang, H.; Gao, N.; Liu, T.; Fang, Y.; Qi, B.; Wen, Q.; Zhou, J.; Jia, L.; Qiao, H. Effect of cytochrome b5 content on the activity of polymorphic CYP1A2, 2B6, and 2E1 in human liver microsomes. PLoS ONE 2015, 10, e0128547. [CrossRef]

50. Takahashi, K.; Oda, Y.; Toyoda, Y.; Fukami, T.; Yokoi, T.; Nakajima, M. Regulation of cytochrome b5 expression by miR-223 in human liver: Effects on cytochrome P450 activities. Pharm. Res. 2014, 31, 780-794. [CrossRef]

51. Sacco, J.C.; Trepanier, L.A. Cytochrome b5 and NADH cytochrome b5 reductase: Genotype-phenotype correlations for hydroxylamine reduction. Pharmacogenet. Genom. 2010, 20, 26. [CrossRef]

52. Ruiz, J.N.; Belum, V.R.; Creel, P.; Cohn, A.; Ewer, M.; Lacouture, M.E. Current practices in the management of adverse events associated with targeted therapies for advanced renal cell carcinoma: A national survey of oncologists. Clin. Genitourin. Cancer 2014, 12, 341-347. [CrossRef] [PubMed]

53. Ferrer, F.; Solas, C.; Giocanti, M.; Lacarelle, B.; Deville, J.L.; Gravis, G.; Ciccolini, J. A simple and rapid liquid chromatography-mass spectrometry method to assay cabozantinib in plasma: Application to therapeutic drug monitoring in patients with renal cell carcinoma. J. Chromatogr. B Anal. Technol. Biomed. Life Sci. 2020, 1138, 121968. [CrossRef] [PubMed]

54. Miles, D.; Jumbe, N.L.; Lacy, S.; Nguyen, L. Population pharmacokinetic model of cabozantinib in patients with medullary thyroid carcinoma and its application to an exposure-response analysis. Clin. Pharmacokinet. 2016, 55, 93-105. [CrossRef] [PubMed]

Publisher's Note: MDPI stays neutral with regard to jurisdictional claims in published maps and institutional affiliations.

(C) 2020 by the authors. Licensee MDPI, Basel, Switzerland. This article is an open access article distributed under the terms and conditions of the Creative Commons Attribution (CC BY) license (http://creativecommons.org/licenses/by/4.0/). 